\title{
Socio-cultural determinants of meal size and frequency
}

\author{
BY JOHN M. DE CASTRO \\ Department of Psychology, Behavior and Neurobiology Program, Georgia State University, \\ Atlanta, GA 30303, USA
}

\begin{abstract}
Total energy intake and the frequency and size of meals are profoundly influenced by the sociocultural context in which it occurs. Simply eating with one other person increases the average amount ingested in meals by $44 \%$ and with more people present the average meal size grows even larger. The impact of social facilitation of energy intake on the individual appears to result from genetic effects both on the individuals' sensitivity to the presence of other people and also on the number of other people an individual tends to eat with. Culture markedly affects the choice of foods in the diet and the pattern of meals over the day. However, many of the social, psychological and physical variables that influence intake are similar across cultures.
\end{abstract}

Meal size: Meal frequency: Eating behaviour

Human behaviour is profoundly affected by social influences. 'Of all the stimulation that impinges on the organism in its lifetime, stimulation from social sources is most important' (Zajonc, 1980). An individual may exhibit quite different behaviours in different social contexts, being quiet and reflective when alone, boisterous outgoing and rebellious with friends, or obedient and retiring in the presence of authority figures and the nature of these responses may vary in different cultures. Not only which behaviours are emitted but also their magnitude is influenced by the social context. In general, the presence of other people tends to increase the expression of simple behaviours while it tends to interfere with complex behaviours (Zajonc, 1980). It is this effect on the magnitude of behaviour that is generally referred to as social facilitation or inhibition. Social facilitation of behaviour has been defined as 'increments in the frequency or intensity of responses already learnt by the individual, shown in the presence of others usually engaged in the same behaviour' (Crawford, 1939). The present paper will attempt to review what is known regarding social facilitation and inhibition of intake in normal human subjects.

Simple behaviours tend to be increased in magnitude by social influences. Since eating is a very simple behaviour, it would be expected that more would be eaten when dining with others present. Such an effect has long been known to occur with animals, who eat more in the presence of other animals than they eat when alone. This phenomenon was demonstrated by Bayer in 1929. He allowed a chicken to completely satiate, eating as much wheat as it wanted. He then introduced a hungry chicken who began to eat. The first chicken, although just satiated, began to eat again immediately (Bayer, 1929). This exact same phenomenon has been replicated in pigs (Hsia \& Wood-Gush, 1984). The general phenomenon of social facilitation of eating has subsequently been demonstrated in a large variety of species from chickens (Tolman, 1964; Tolman \& Wilson, 1965; Rajecki et al. 1975), fish (Welty, 1934), rats (Harlow, 1932; Hoyenga \& Aeschleman, 1969), gerbils (Forkman, 1991), puppies (James, 1960), to primates (Harlow \& Yudin, 1933). 
Even though the animal research clearly demonstrated that social facilitation was a robust phenomenon, it was still believed that somehow people were different. Indeed, Harlow (1932) wrote '.. in the presence of individuals like ourselves... eating is influenced, probably not so much as to quantity as to appreciation. A good meal tastes better if we eat it in the company of friends'. Food intake by human subjects was looked upon as fundamentally different from that of animals. As a colleague of mine commented 'animals feed, humans dine!' As a result, the lively research on social facilitation of food intake in animals was not paralleled by similar research in human subjects.

\section{LABORATORY STUDIES OF SOCIAL FACILITATION OF EATING IN HUMAN SUBJECTS}

In spite of this thinking, findings have emerged from the laboratories suggesting that social facilitation also affects the eating behaviour of human subjects. Frank (1944) demonstrated that subjects would eat simply in response to an instruction to eat, even when they were told that they were participating in an experiment on persuasion and it didn't matter whether they ate or not. Much like Bayer's chickens, people, when paired with someone who eats a large amount of food, markedly increase their intake. Nisbett \& Storms (1972) invited subjects to eat crackers in a taste test. They 'tasted' the crackers alone or paired with a confederate who ate either one or twenty crackers. Normal weight subjects ate $29 \%$ less with the low-intake 'model' and $25 \%$ more with the high-intake 'model' than when alone. Using a very similar modelling technique, Conger $e t$ al. (1980) found an even larger effect. Subjects exposed to a high-intake 'model' ate $86 \%$ more crackers than with a lowintake 'model'. In addition, they demonstrated a comparable inhibitory effect. Subjects paired with someone who did not eat any crackers decreased their intake by $42 \%$.

Polivy et al. (1979) described a similar modelling effect. They had $5 \mathrm{~h}$-fasted subjects fill themselves with sandwich quarters in preparation for a 'taste test'. When the subjects were paired with a confederate who ingested eight sandwich quarters they ate $57 \%$ more than when the confederate only ate two sandwich quarters. The influence of the 'model' persisted into the 'taste test', with the subjects exposed to the high-intake 'model' eating $31 \%$ more nuts than those exposed to a low-intake 'model'. Employing a similar modelling technique, Goldman et al. (1991) demonstrated $50 \%$ greater intake with a high-intake 'model' than with a low-intake 'model' in subjects who were deprived of food for $24 \mathrm{~h}$.

The intake of a subject also appears to be affected by the nature of a companion. De Luca \& Spigelman (1979) had a non-obese or obese 'model' always eat the same amount of candy while filling out a questionnaire. Obese subjects tended to eat more with the obese 'model' than with the non-obese 'model', while non-obese subjects were unaffected by the 'model's' weight. In addition, Clendennen et al. (1994) demonstrated that when subjects ate with friends they ate more than when paired with strangers or alone. Gender also appears to influence the response to eating with a companion. During a 'get acquainted' session in the lab, female subjects ate $75 \%$ less when accompanied by a desirable male than they ate when accompanied by an undesirable companion (Mori et al. 1987). A comparable effect was not apparent for males. Also, Pliner \& Chaiken (1990) found that both male and female college students ate less in the presence of an attractive member of the opposite sex.

It has been observed that the amount that a person eats is affected by the mere presence of other people eating with them. In the laboratory, subjects, regardless of gender, ate $94 \%$ more ice cream in groups than when eating alone (Berry et al. 1985). In more naturalistic settings subjects have also been observed to be affected by the presence of other people. 
Edelman et al. (1986) compared the amount eaten in a cafeteria to that ingested in isolated conditions. They found that both obese and non-obese people ate $48 \%$ more in the cafeteria than when alone. Krantz (1979) performed a naturalistic observation in a university cafeteria of the effect of eating with others on the intake of obese and non-obese subjects. Obese subjects purchase less food when accompanied by others than when alone. On the other hand, non-obese subjects do the opposite. They purchase more food when accompanied by companions than when alone.

\section{SOCIAL FACILITATION OF SPONTANEOUS EATING IN FREE-LIVING HUMAN SUBJECTS}

The laboratory evidence makes a compelling case that social influences can produce very large increases or decreases in the amounts of food ingested. The magnitude of these effects is quite striking. However, the evidence is from studies of adjunctive intake, snacking, or from, at best, a single lunch meal. This raises the question as to whether these results, mainly produced under very artificial conditions, generalize to the natural, everyday, intakes of normal people and can raise or lower overall intake over sustained periods of time.

To investigate whether social facilitation influences peoples' intake outside the laboratory, we re-analysed the diet-diary data that were collected in the previous studies (de Castro et al. 1986, 1990; de Castro, 1987a, b, 1990, 1991a, b, c, 1993b, e, 1994a, b; de Castro \& de Castro, 1989; de Castro \& Brewer, 1992). These data were collected by asking subjects to record in a diary everything they either ate or drank, the amounts and the method of preparation, the time of eating, and the number and nature of other people present at the meal, for a period of seven consecutive days. For a review of methodology and the reliability and validity of the diet-diary procedure, see de Castro (1994b). The participants consisted of over 700 North Americans, from diverse geographical regions and ranging in age from 18 to 70 years. We simply looked at the amounts ingested in meals eaten alone $v$. those eaten with other people present. It was found that the meals eaten with other people present were on the average $44 \%$ larger than meals eaten alone (de Castro \& de Castro, 1989) and included larger amounts of carbohydrate, fat, protein, and alcohol. In addition, it was shown that this was an orderly phenomenon. The number of people present had a significant positive correlation with the amount eaten in the meal. This correlation is called the social correlation and indicates that the more people that are present at a meal, the more that will be eaten. Multiple linear-regression analysis revealed that taking into consideration social facilitation does not alter the impact of any of a number of other influences on meal size, suggesting that the presence of other people affects food intake independent of other salient influences (de Castro \& de Castro, 1989).

Finally, social facilitation appears to affect the size of meals and not the frequency of eating, as the number of people eating with a participant during $1 \mathrm{~d}$ does not appear to be related to the number of meals ingested during that day. In general, we have found that meal size is elastic and can be influenced by psychological and environmental factors. But, meal frequency appears to be relatively unaffected by factors that influence overall intake.

It is possible that this relationship between the presence of other people and meal size is artifactual. The positive correlation could result from a covariation produced by a third factor. In particular, the time of day may be responsible. Breakfast is the smallest meal of the day and may be eaten with the fewest other people present, while dinner is the largest meal and may have the greatest number of other people present. It may also occur as a result of alcohol intake which may increase the energy content of meals eaten with other people. Additionally, snacks are small and generally eaten alone, while meals are in 
general larger and more likely to be eaten with others. Another possible explanation is that meals eaten in restaurants may be larger and eaten with more other people than meals eaten at home, which, in turn, may be larger and more social than meals eaten elsewhere. Still another possibility is that meals eaten on weekends may be larger and eaten with more other people present than meals eaten on weekdays.

To investigate these potential artifactual explanations, meals were identified that occurred under specific conditions. It was demonstrated that, although the covariances existed, they did not account for the social correlation. Strong, positive and significant correlations between meal size and the number of other people present, social correlations, were found separately for meals eaten during the breakfast period, the lunch period, or the dinner period, eaten in restaurants, at home, or elsewhere, eaten accompanied by alcohol intake or without alcohol, for only snacks or only meals (de Castro et al. 1990) or for meals eaten during weekdays or during weekends (de Castro, 1991a).

In order to look more systematically at this relationship, meals eaten alone or with one, two, three, four, five, six, or seven or more people were separated and average meal sizes calculated (de Castro \& Brewer, 1992). As can be seen in Fig. 1, there is an orderly relationship between the number of people present and the meal size. One other person present at the meal was associated with a $33 \%$ increase in meal size, while $47,58,69,70$, 72 and $96 \%$ increases were associated with two, three, four, five, six and seven or more people respectively. The size of the effect is remarkable. The magnitude of these differences is much larger than that obtained in previous research with physiological (de Castro, 1987a; 1988), age (de Castro, 1993e), circadian (de Castro, 1987b), seasonal (de Castro, 1991b), or psychological (de Castro \& Elmore, 1988) variables, suggesting that the most salient factor we have found to be associated with short-term food intake in human subjects is social facilitation.

The orderliness of the effect is also remarkable. It has been shown with many human behaviours that social facilitation can in general be adequately described by a power function (Latane, 1981). We found this to be true for social facilitation of meal size, which can be best represented by the power function meal size $=485 \mathrm{~N}^{0.23}$, where $\mathrm{N}$ is the total number of people present including the subject, and the meal size is expressed in kcal (de Castro \& Brewer, 1992).

Who the individual eats with also influences the amount ingested in the meal (de Castro, 1994a). Females eat significantly more (13\%) when eating with a male than when eating with another female, while males eat the same amount regardless of the gender of their companion. Meals ingested with spouse, family, or friend are significantly larger, 22, 23 , and $14 \%$ respectively, than meals ingested with others but without the companion type, while meals ingested with co-workers were significantly smaller $(16 \%)$.

Even with all this evidence, because of the observational nature of the research, it is not acceptable to conclude that the presence of other people is the cause of the increased intake. In order to establish causation, the number of other people present was actively manipulated by instructing subjects to eat only by themselves for a $5 \mathrm{~d}$ period, eat normally for another $5 \mathrm{~d}$ period, and eat only with other people for a third $5 \mathrm{~d}$ period. The order of these periods was randomized. In comparison with the normal instruction period, the subjects ingested on average $885 \mathrm{~kJ}(11 \%)$ less per $\mathrm{d}$ when instructed to eat alone (Redd \& de Castro, 1992). This suggests that the presence of other people is indeed the cause of the increase in intake at meals. Subsequent laboratory studies have supported the idea of a causal connection between the presence of other people and increased meal size. Clendennen et al. (1994) demonstrated that when subjects were required to eat a test meal with one or three other subjects, they ate significantly more than when alone. 


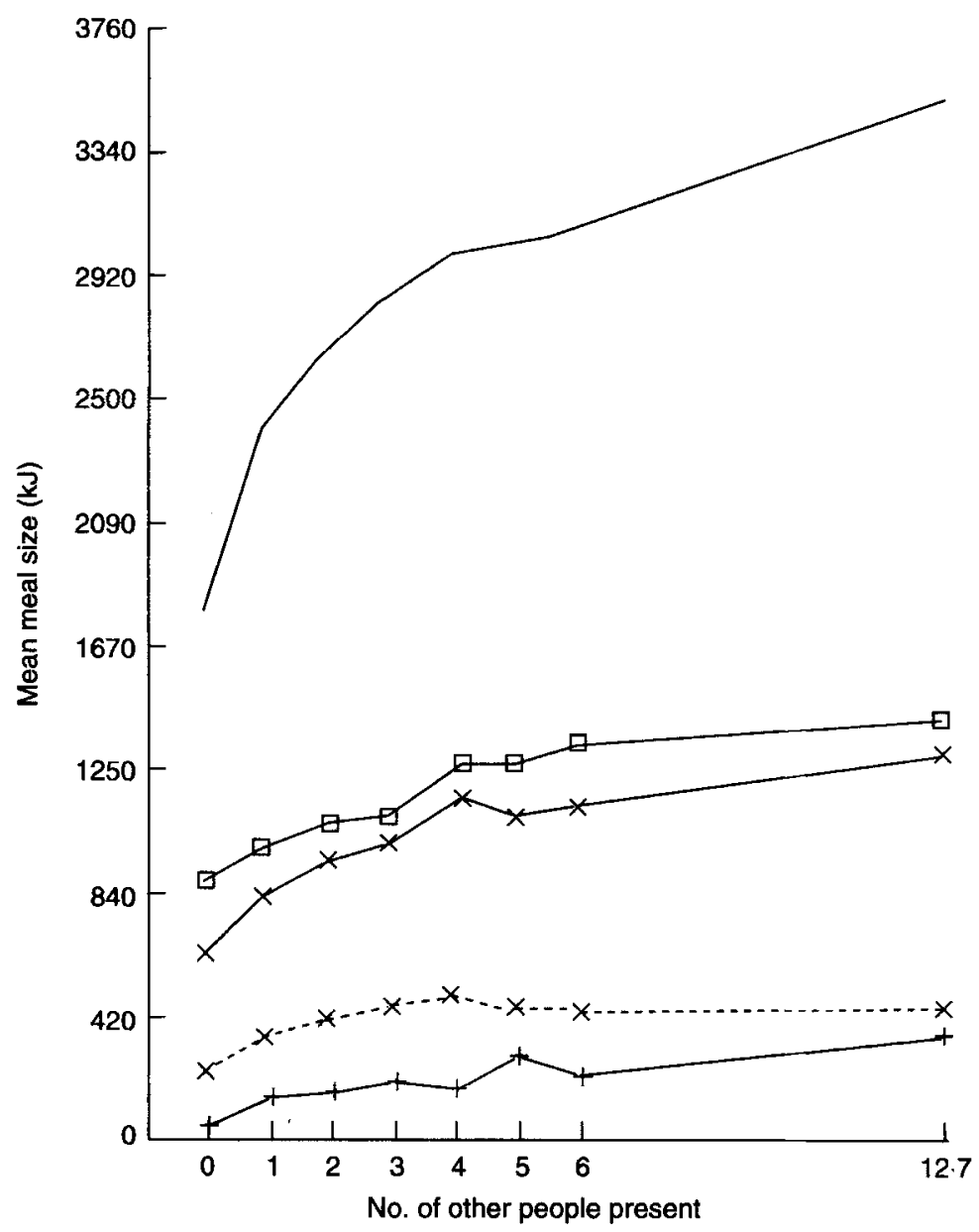

Fig. 1. Mean amount ingested in meals of total food energy $(\longrightarrow)$, carbohydrate $(\square-\square)$, fat $(x-x)$, protein $(x-\cdots x)$ and alcohol $(+-+)$ as a function of the number of other people eating with the subject.

It should be noted that the magnitude of the effect of eating alone $(11 \%)$ is considerably smaller than the magnitude of the effects of social facilitation observed in unmanipulated contexts as reported previously (pp. S41-S42). In fact, the meal sizes reported during the 'manipulated alone' condition were $20 \%$ larger than the 'alone' meals during the normal condition (Redd \& de Castro, 1992). This might indicate that separating naturally-occurring meals that just happen to be eaten alone from those that happen to be eaten with others may overestimate the impact of social facilitation of eating. Alternatively, it might suggest that the subjects compensate, increasing meal size in the 'alone' condition to bring overall intake to more nearly normal levels.

\section{INHERTTANCE OF SOCIAL FACILITATION OF EATING}

Although these social influences would appear on the surface to constitute a major environmental factor influencing intake, there is evidence that inheritance and, thereby, 
physiology may also play a key role in social facilitation. There is a growing body of evidence that body size and food and fluid intake are strongly influenced by heredity. Twin (Feinleib et al. 1977; Bray, 1981; Wade et al. 1981; Stunkard et al. 1986a, 1990) and adoption (Stunkard et al. 1986b; Price et al. 1987; Sorenson et al. 1989) studies have made it evident that body size, weight and height, are primarily determined by inheritance. There is not only a strong genetic influence on body size but also on the composition of the body (Brook et al. 1975; Bouchard et al. 1985, 1986) and even on the metabolic response to feeding (Poehlman et al. 1986a, bc), including the tendency to store energy as either lean tissue or fat (Bouchard et al. 1990; Bouchard, 1991).

Whether and how the genes might influence food and fluid intake was investigated by analysing the diet-diary reports of the eating behaviour of over fifty pairs of male and fifty pairs of female adult identical twins and over fifty pairs of male, fifty pairs of female, and fifty mixed-gender pairs of adult fraternal twins, who lived and ate separately (de Castro, 1997). Based on these data, heritabilities were calculated, employing linear structuralmodelling techniques, for social factors and intakes and their correlations. It was found that the genes influence not only body size but also the overall amount of food and fluid ingested, the number, timing, and composition of meals and draughts (de Castro, 1993a), and even the amounts of particular beverages ingested (de Castro, 1993d). These genetic influences on intake were shown to be mostly independent of body size, and inheritance was found to influence meal size and frequency even when overall daily intakes were considered in the model (de Castro, 1993c).

Whether and how the genes might influence the social facilitation of intake was investigated by analysing this same data set and calculating heritabilities for the number of other people eating with the participant and the relationship of the number of people and meal size. It was found that heredity had an influence on the number of people an individual tends to eat with (Fig. 2). This was a relatively large and surprising effect which accounted for over $20 \%$ of the variance in the total number of other people eating with the individual. This is quite remarkable given that the number of other people present would, at least on the surface, appear to be primarily due to environmental conditions. In addition, it was found that heredity not only influenced the total number of people present but also the nature of the companions with which the individuals ate. This was especially true for family, friends and spouse, where heredity accounted for over $25 \%$ of the variance in the likelihood of eating with each of these companions (de Castro, 1997).

It was also found that the genes influence the degree of impact these companions have on the amount ingested in the meals. The degree of association between the number of eating companions and meal size was found to be heritable. Evidence was provided by significant heritabilities for the social correlations (Fig. 2). In addition, the amount of increase in meal size produced by each companion was also found to be heritable. This was shown by significant heritabilities that were calculated for the slopes of the regression equations relating the number of people present to the meal size. These influences had a large impact on the amount eaten in meals. The slopes indicate that the amount in a meal was on average increased by over $20 \%(292 \mathrm{~kJ})$ for each other person present at the meal. In addition, there were large individual differences in the magnitudes of the slopes and over $30 \%$ of the variance in these differences was accounted for by heredity (de Castro, 1997). Hence, both the amount of variance in meal size accounted for by the presence of other people and the amount of influence of each of these companions on the amount eaten would appear to be significantly affected by the genes. 

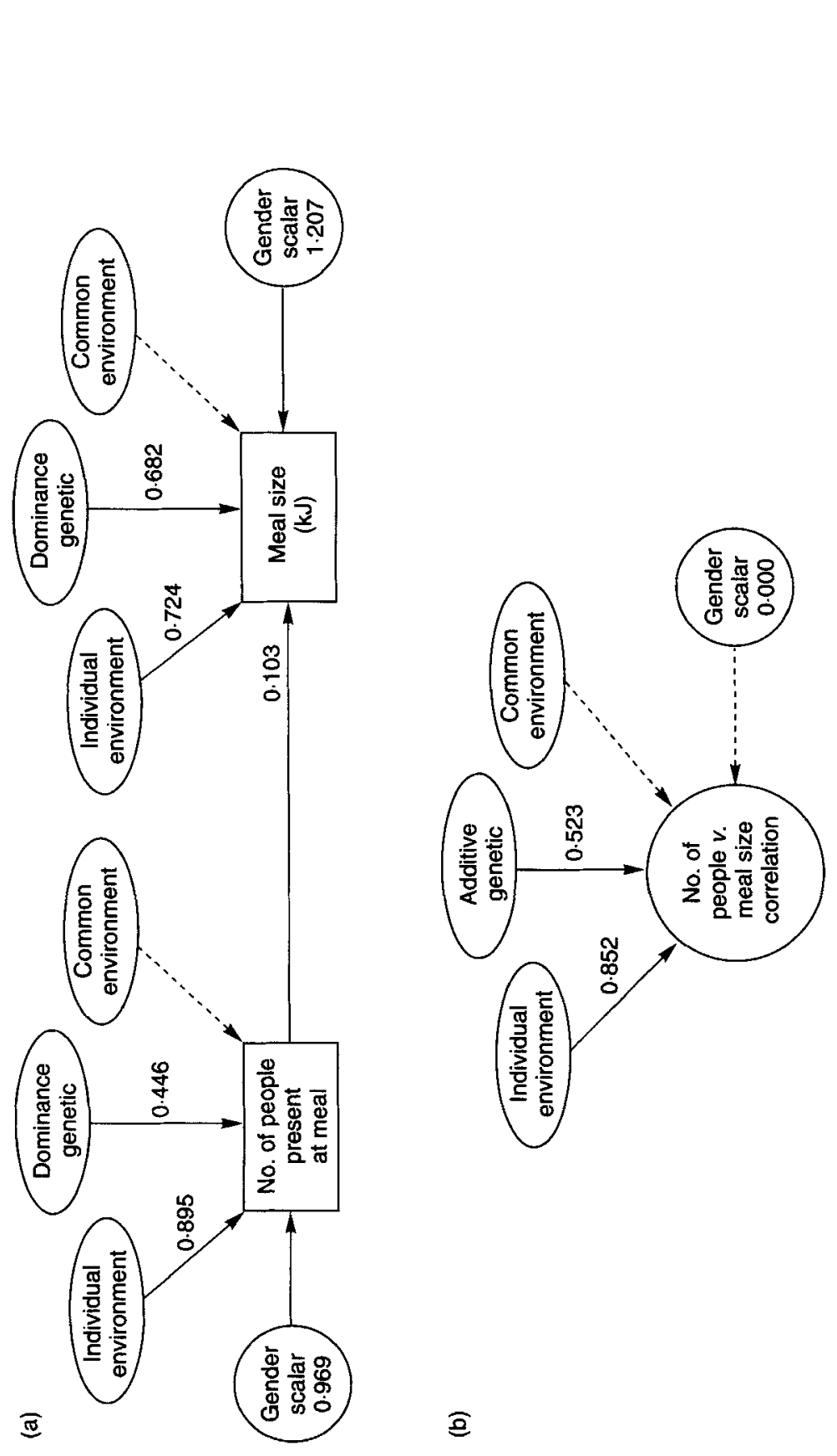

焉

蛋

距

若

:

过

s.

空

氜

证

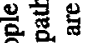

送

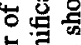

喜䓴

定

实

छ

ज़ ซึ

है

量守

릉

远

光 응

용

क

붕

氜过

承

클

은

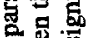

농 글

㐘

急.

त क्षै क

这导 


\section{EXPLANATIONS OF SOCIAL FACILITATION OF EATING}

The research to date has demonstrated that social facilitation is a ubiquitous and salient influence on food intake that operates in the real everyday environments of normal people causing increased consumption of nutrients. Of all the myriad of stimuli that affect the ad libitum intake of human subjects, social facilitation is the most powerful we have yet discovered (de Castro \& de Castro, 1989). The question remains as to how the presence of other people may operate on the individual to influence the amount eaten in a meal. There are a number of theoretical explanations. However, only a few of these fit the available data.

One possibility is that the causation is in the reverse direction. Rather than the presence of other people producing an increase in intake, it is possible that large meals are scheduled with other people while small meals are scheduled alone. This alternative cannot be addressed within the observational data set. However, manipulative studies have demonstrated that when the number of people present is actively manipulated there is an increase in the amount ingested (Redd \& de Castro, 1992; Clendennen et al. 1994). Hence, although scheduling of large meals as social meals cannot be eliminated as an explanation and such scheduling may indeed explain some of the social facilitation phenomenon, there is a clear causal impact of the presence of other people on the amount ingested.

Social facilitation might operate by producing disinhibition; the presence of a companion relaxing the individual, thereby releasing behaviour from inhibition (Rajecki $e t$ al. 1975). Observing someone else eating may remove constraints on eating that otherwise would limit the amount ingested. Social factors might also act by distracting the individual from the eating process and thereby release cognitive restraints. This notion would predict a greater level of calmness with social meals producing a release of restraints on eating. The results of the analyses of the diet-diary data tend to support this hypothesis. It would predict that the better known the companion the greater the relaxation and, thus, the greater the facilitation of intake. Indeed, social facilitation was greatest when the subjects selfreported greater calmness. This occurred when they ate with friends, family, or a spouse. On the other hand, when the subjects self-reported greater anxiety and less calmness, eating with work associates, classmates, or other companions, social facilitation had the least impact on intake (de Castro, 1994a). Hence, the disinhibition hypothesis is a viable explanation of social facilitation of eating.

Alternatively, the presence of other people might simply extend the amount of time spent at a meal and, thus, increase the amount eaten (de Castro, 1990). The verbal interactions occurring during social meals may simply cause a person to linger over the meal and, as a result, eat more. This notion predicts that the rate of intake should be the same regardless of the social conditions, but the duration of the meal would be extended when other people were present. Indeed, the diet-diary data indicate that the duration and not the rate of intake increases when meals are eaten socially (de Castro, 1990; de Castro \& Brewer, 1992; see Fig. 4). Further, this hypothesis is also supported by diet-diary findings that social facilitation occurs maximally when eating with friends, family, or a spouse (de Castro, 1994a). In addition surreptitious observations of people in restaurants (Sommer \& Steele, 1997) and coffee-houses (Sommer \& Sommer, 1989) demonstrated that the length of the stay was positively related to the group size. Also, linear structural modelling of social effects on meal size suggest that the presence of other people does not have a direct effect on meal size, but rather an indirect effect that is mediated by meal duration (Feunekes et al. 1995). Hence, the time-extension hypothesis is also a viable explanation of social facilitation of food intake. 


\section{CROSS-CULTURAL STUDIES OF SPONTANEOUS EATING IN FREE-LIVING HUMAN SUBJECTS}

A serious limitation with previous research results from the fact that most of the data were obtained in North America. Specific patterns of intake, food choices, and cuisine are present in North America that are different from those found in other areas including Europe. As a result, it is unclear to what extent the results reflect universal, fundamental regulatory processes, or simply reflect established socio-cultural patterns of intake. Thus, it is important to study ad libitum eating behaviour in other cultures in order to establish the generalizability or cultural specificity of the previous findings.

As a beginning towards addressing this issue we compared the eating behaviours of free-living college students in France and The Netherlands to those of comparable North Americans (de Castro et al. 1997). There were obvious and marked differences in the cuisines and typical foods ingested in the three cultures. However, of interest was the extent to which overall energy intakes or proportions of macronutrients differed between the cultures and the extent to which similar or different factors tended to influence intake.

Comparisons between the students' intakes demonstrated rather marked differences between the overall intakes and eating patterns existing in the three cultures. Overall intakes, even when adjusted for body weight were found to be considerably higher for the Dutch students (mean 12.7 and 9.1 MJ for males and females respectively) than for either the French (mean 9.9 and $7.8 \mathrm{MJ}$ for males and females respectively) or the American students (mean 10.0 and $7.2 \mathrm{MJ}$ for males and females respectively) who did not differ. The Dutch students ate a diet that was relatively high in carbohydrate and low in fat and protein, while the French students ingested a diet that was relatively high in fat.

The Dutch students not only differed in the overall amounts ingested but also in the pattern of intake. They showed a nibbling pattern of intake. The higher overall intake resulted from the Dutch students ingesting a large number of small meals separated by relatively short intervals each day (Fig. 3). These small meals were eaten with more other people present and at a slower rate but for a longer period of time than the French or the American students. Even though in general the meals eaten by the Dutch students were small, relative to the amount of time since their last meal, they ate a greater amount than the French or the American students. This resulted in higher deprivation ratios; meal size divided by the duration of the previous interval. Also, after these small meals, the Dutch students waited a shorter period of time before eating again, even when the inter-meal interval was viewed relative to the size of the meal. This resulted in smaller satiety ratios (duration of the after-meal interval divided by the meal size). Hence, marked cultural differences were present in the amounts, composition, and pattern of intake. This is probably due to the Dutch culture in general and not just to the student culture, as the Dutch elderly have also been found to have higher meal frequencies than the elderly from other European countries (Schlettwein-Gsell et al. 1991).

The diurnal distribution of intake appears to be a culturally-specific pattern. The American students showed a pattern of increasing meal sizes over the day (Fig. 3(b)). This pattern is exaggerated with the Dutch students. They eat smaller meals during the day but larger meals in the evening. Again there is evidence to suggest that this is due to the Dutch culture in general and not just to the student culture, as the Dutch have been found to have increasing meal sizes over the day (Zo eet Nederland, 1992) and the Dutch elderly have been found to eat a larger proportion of their daily intake in the evening than the elderly from other European countries (Schlettwein-Gsell et al. 1991). But unlike the Americans, their pre-meal intervals are relatively constant over the day (Fig. 3(a)). The French students ate larger meals during the early afternoon period than the Dutch or the American students, 
(a) Mean meal size

(b) Pre-meal interval
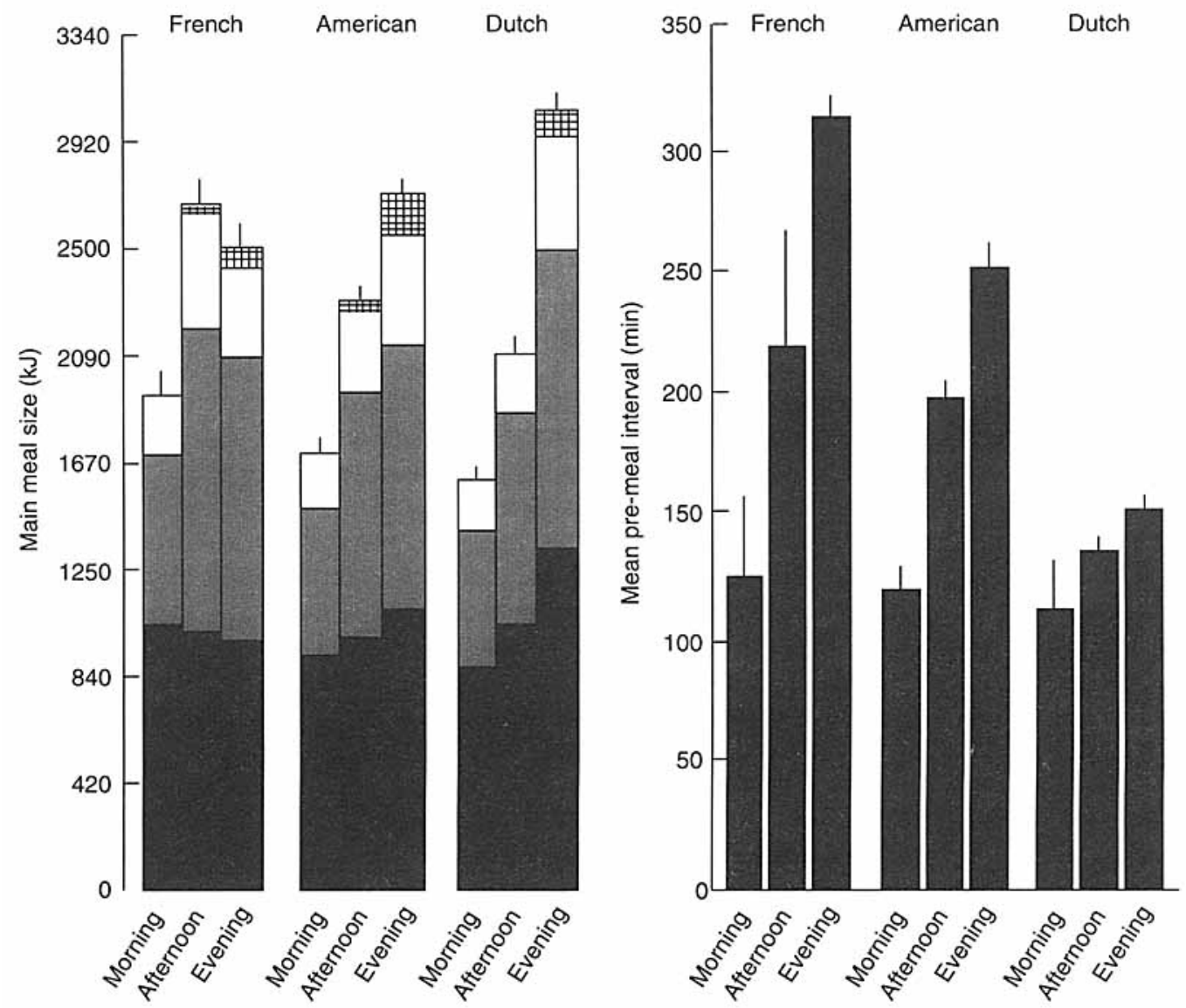

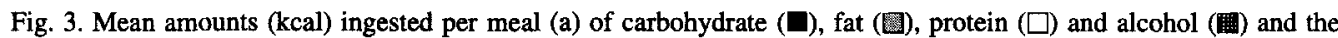
average duration of the interval before the meal (b) for meals eaten in the morning (06.00-11.00 hours), noontime (11.00-15.00 hours), and evening (17.00-21.00 hours) periods for the French, American and Dutch groups. All meals were defined by the minimum $45 \mathrm{~min} / 50 \mathrm{kcal}$ criteria. Values are means with their standard errors represented by vertical bars.

but there is no further increase in meal size in the evening. Also, the French have longer after-meal intervals, particularly after meals eaten in the early afternoon. Thus, it is clear that the diurnal meal pattern depends on the culture and is not universal.

Cross-cultural comparisons usually involve some procedural differences that may account for apparent cultural effects and this was the case in the present study. Recruitment methods differed. The French and the Dutch students were paid for their participation, while the American students received only course credit and dietary feedback. The Dutch students were screened more rigorously than the Americans or the French, in that students with high dietary restraint scores were excluded. It is possible that procedural differences could explain the differences in the intakes found between the nationalities. However, even though the reported differences are to some extent interesting, the most important findings were the great similarities between the nationalities in the students' responses to the social, 
psychological, and physical variables that influence intake. The fact that these similarities could be discerned even with procedural differences, speaks to the strength and robustness of the phenomena.

The correlations and slopes of the regression equation between the time of day and the meal size were found to be small and positive regardless of the culture (Fig. 4). Also, the social correlation between the number of people present at meals and the amount ingested in the meals (de Castro \& de Castro, 1989; de Castro \& Brewer, 1992) was significant and positive for all three nationalities (Fig. 4). The Dutch students ate with significantly more people present (mean 2.15) than the French (mean 1.42) or the American students (mean 1.53). However, the magnitudes of the correlations did not differ. This suggests that social facilitation of food intake may result from the operation of a common physiological or cognitive process.

The subjective state of hunger has been shown to be positively correlated with the amount eaten in the meal (de Castro \& Elmore, 1988). However, the self-ratings of hunger differed between nationalities. On a seven-point sated-hungry Likert scale, the American students indicated that they were hungrier (mean 5.15) at the beginning of the meal and less sated at the end (mean 2.73) than the French (mean 4.58 and 1.80 respectively) or the Dutch students (mean 4.28 and 2.43 respectively). The differences in level of subjective hunger notwithstanding, all nationalities showed strong significant correlations between the meal size and both the pre-meal and after-meal ratings of hunger and their change over the meal (Fig. 4). Even when immersed in a multiple regression, pre-meal hunger has a strong positive relationship with meal size for all nationalities. This suggests that the subjective hunger-intake relationship is present regardless of culture and may also represent the operation of a common process.

The amount of food energy and its composition can be estimated by applying a computer model of stomach emptying to the known amount ingested and the amount of time since the ingestion (de Castro et al. 1986). Using this procedure, the Dutch were estimated to have more in their stomachs before the meals (mean $972 \mathrm{~kJ}$ ) than the French (mean $234 \mathrm{~kJ}$ ) or Americans (mean $325 \mathrm{~kJ}$ ). Even though there were differences between the nationalities in the magnitudes of the correlations and slopes, all three nationalities showed significant negative correlations and slopes between stomach content and pre-meal and after-meal hunger and negative univariate and multivariate relationships between stomach content and meal size (Fig. 4). This suggests that the relationships between the stomach contents and subjective hunger or intake are present regardless of culture and, therefore, may be indicative of the operation of a common process.

The duration of the interval since the previous meal has been shown to have a small positive correlation with the amount eaten in the meal (de Castro et al. 1986). Again, there are large group differences, with the Dutch having significantly shorter intervals between meals than the other nationalities (Fig. 3). However, regardless of these differences in level, the three nationalities show equivalent relationships between the pre-meal interval and the meal size (Fig. 4).

These results suggest that, although cultural effects permeate the eating pattern, many of the social, psychological and physical variables that influence intake are similar across cultures. It should be noted that this conclusion needs be tempered by the fact that the degree of cultural diversity present in the study was limited. All participants were university students in affluent Western industrialized societies and most were Caucasian. As a result, it cannot be concluded that the relationships found to be present across French, American, and Dutch culture would necessarily be found outside Western cultures, in nonCaucasian racial groups, or outside student samples. Indeed, eating disorders, while 


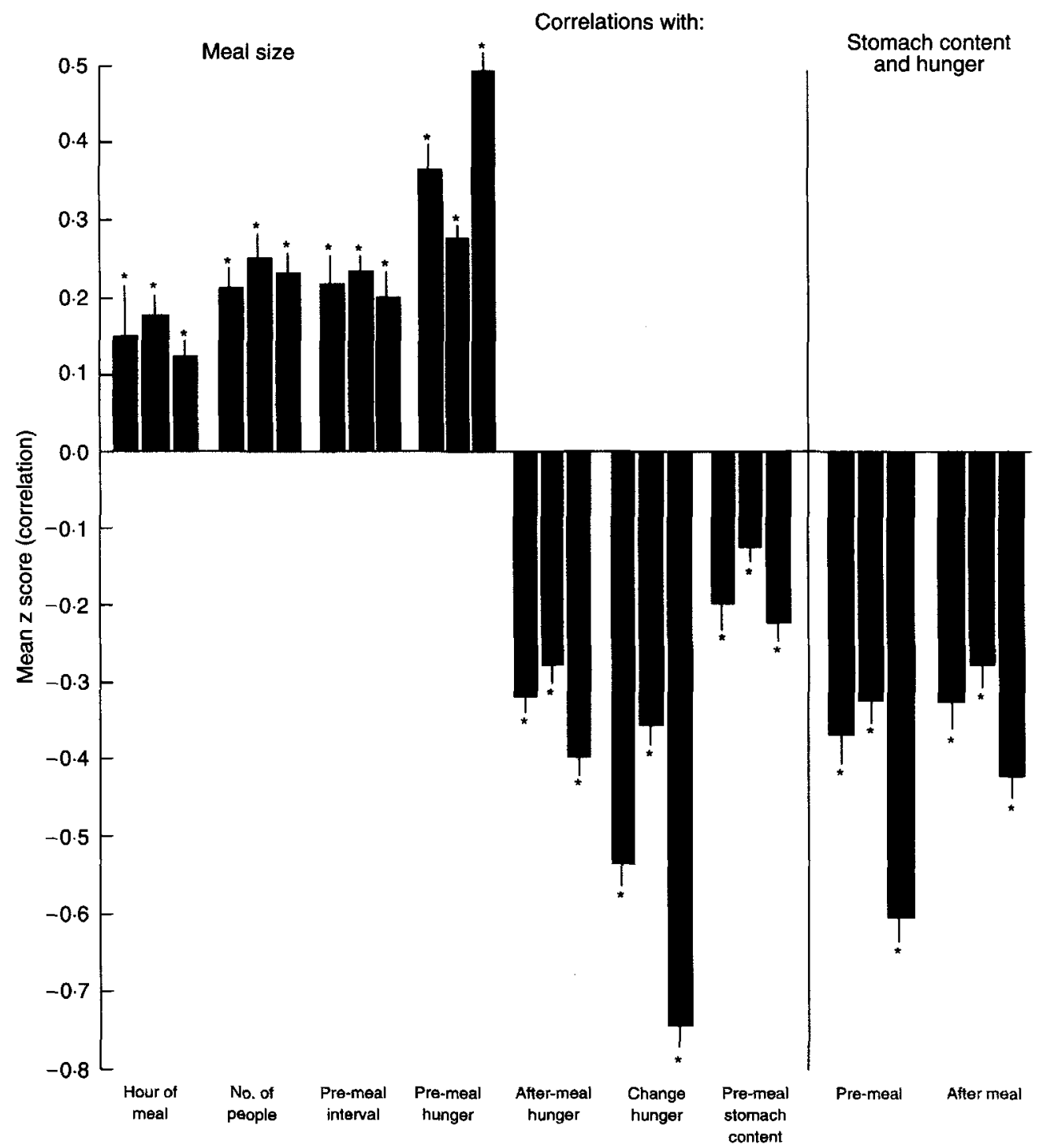

Fig. 4. Mean correlations for the regressions of the amounts ingested in the meals $v$, the mean hour of the beginning of the meals, the number of other people present at the meals, the duration of the interval before the meal, the self-ratings of hunger before the meals, after the meals, and the change over the meal, and the estimated pre-meal stomach content of the food energy, and the correlations between the estimated pre-meal stomach content and premeal hunger, and between the estimated after-meal stomach contents and after-meal hunger. Each set of three values represents means for French, Dutch and American groups respectively. All meals were defined by the minimum $45 \mathrm{~min} / 50 \mathrm{kcal}$ criteria. Values represent means with their standard errors represented by vertical bars. Mean values were significantly different from zero $(t$ test): $* P<0.05$.

common in Western countries are relatively rare in non-Western countries (King, 1993) and even within Western countries are much less common in black subjects (Abrams et al. 1993). However, a good deal of diversity in intake was found and yet the fundamental relationships between a number of social, psychological and physical variables and eating were present regardless of the diversity. Hence, these relationships are robust in the face of 
differences in diurnal patterns and varying meal frequencies. These results then may be looked upon as a first step towards establishing which controls of intake are culture specific and which are universal.

\section{DIRECTIONS FOR FUTURE RESEARCH}

Future research is needed to test explanatory models. A factorial study manipulating both social conditions and the duration of meals would be useful for testing the time-extension model of social facilitation. In addition, the concurrent measurement of physiological variables such as heart rate, blood pressure, etc. in conjunction with the manipulation or observation of different social conditions of eating could be useful for testing the disinhibition model. Future research is also needed to extend and replicate the findings in a variety of other cultures. In particular, since all the current studies were performed in Western cultures with primarily Caucasian subjects, there is a need to investigate social influences on eating in African, Oriental, and Hispanic cultures and in non-Caucasian racial groups.

There is a need for further study of the physiological-genetic basis of social effects. Since the genes influence behaviour by dictating physiological structure, investigations into the nature of physiological reactions to social stimuli may provide clues as to the nature of the inherited factors. In addition, modern molecular-genetic techniques may allow the identification of specific genes associated with responsivity to social effects on eating, which in turn could lead to the identification of the inherited physiological characteristics underlying the effects.

Another fertile area for investigation is the applications of social influences on eating to alter the eating behaviour of target populations. Before applying the manipulation of social factors to chronically alter intake, there is a need to study the operation of social factors over time frames longer than 1 week. If long-term regulatory factors are found to eventually counter the effects of an altered social environment, then the manipulation of social factors would not be a useful technique for the chronic alteration of intake. Target populations should include the elderly, where undernutrition represents a serious health concern, and the obese, where a reduction in intake is desired. Research could also be conducted on the application of social influences to areas of required dietary control such as diabetes and renal failure (dialysis patients). Soldiers in the field under-ingest nutrients and social facilitation may be a useful strategy to increase their intake.

Finally, there is also a need to develop better data-collection procedures. Diet-diary techniques underestimate actual intakes (Goran \& Poehlman, 1992; Livingstone et al. $1990,1992)$. Hence, new methods need to be developed to increase accuracy. In addition, current techniques do not work well with unmotivated or illiterate populations. This greatly restricts research. In particular, there is a great need to develop data-recording techniques that do not require large amounts of effort on the part of the subjects. Small video cameras attached to the subjects and monitored remotely or other forms of telemetry equipment might be useful for monitoring real-life eating and their social conditions.

\section{REFERENCES}

Abrams, K. K., Allen, L. R. \& Gray, G. J. (1993). Disordered eating attitudes and behaviours, psychological adjustment, and ethnic identity: a comparison of black and white female college students. International Journal of Eating Disorders 14, 49-57.

Bayer, E. (1929). Beiträge zur Zweikomponententheorie das Hungers (Contributions to the two-component theory of hunger). Zeitschrift für Tierpsychologie 118, 283-349 
Berry, S. L., Beatty, W. W. \& Klesges, R. C. (1985). Sensory and social influences on ice cream consumption by males and females in a laboratory setting. Appetite 6, $41-45$.

Bouchard, C. (1991). Current understanding of the etiology of obesity: genetic and nongenetic factors. American Journal of Clinical Nutrition 53, 1561S-1565S.

Bouchard, C., Perusse, R., Tremblay, L. \& Leblanc, C. (1986). Inheritance of body composition and fat distribution. American Journal of Physical Anthropology 179, 61-75.

Bouchard, C., Savard, R., Depres, J.-P., Tremblay, A. \& Leblanc, C. (1985). Body composition in adopted and biological siblings. Human Biology 57, 61-75.

Bouchard, C., Tremblay, L., Depres, J.-P., Nadeau, A., Lupien, P. J., Theriault, G., Dussault, J., Moorjani, S., Pinault, S. \& Fournier, G. (1990). The response to long-term overfeeding in identical twins. New England Journal of Medicine 322, 1477-1482.

Bray, G. A. (1981). The inheritance of corpulence. In The Body Weight Regulatory System: Normal and Disturbed Mechanisms, pp. 185-195 [L. A. Chiofi, W. P. T. James and T. R. Van Itallie, editors]. New York: Raven Press.

Brook, L. G. D., Huntley, R. M. C. \& Slack, J. (1975). Influence of heredity and environment in determination of skinfold thickness in children. British Medical Journal 2, 719-721.

Clendennen, V. I., Herman, C. P. \& Polivy, J. (1994). Social facilitation of eating among friends and strangers. Appetite 23, 1-13.

Conger, J. C., Conger, A. J., Costanzo, P. R., Wright, K. L. \& Matter, J. A. (1980). The effect of social cues on the eating behaviour of obese and normal subjects. Journal of Personality 48, 258-271.

Crawford, M. P. (1939). The social psychology of vertebrates. Psychology Bulletin 36, 407-446.

de Castro, J. M. (1987a). Macronutrient relationships with meal patterns and mood in the spontaneous feeding behavior of humans. Physiology and Behavior 39, 561-569.

de Castro, J. M. (1987b). Circadian rhythms of the spontaneous meal patterns, macronutrient intake, and mood of humans. Physiology and Behavior 40, 437-446.

de Castro, J. M. (1988). Physiological, environmental, and subjective determinants of food intake in humans: a meal pattern analysis. Physiology and Behavior, 44, 651-659.

de Castro, J. M. (1990). Social facilitation of duration and size but not rate of the spontaneous meal intake of humans. Physiology and Behavior 47, 1129-1135.

de Castro, J. M. (1991a). Social facilitation of the spontaneous meal size of humans occurs on both weekdays and weekends. Physiology and Behavior 49, 1289-1291.

de Castro, J. M. (1991b). Seasonal rhythms of human nutrient intake and meal patterns. Physiology and Behavior 50, 243-248.

de Castro, J. M. (1991c). Weekly rhythms of spontaneous nutrient intake and meal pattern of humans. Physiology and Behavior 50, 729-738.

de Castro, J. M. (1993a). Genetic influences on daily intake and meal patterns of humans. Physiology and Behavior 53, 777-782.

de Castro, J. M. (1993b). The effects of the spontaneous ingestion of particular food or beverages on the meal pattern and overall nutrient intake of humans. Physiology and Behavior 53, 1133-1144.

de Castro, J. M. (1993c). Independence of genetic influences on body size, daily intake, and meal patterns of humans. Physiology and Behavior 54, 633-639.

de Castro, J. M. (1993d). A twin study of genetic and environmental influences on the intake of fluids and beverages. Physiology and Behavior 54, 677-687.

de Castro, J. M. (1993e). Age related changes in natural spontaneous food intake and hunger in humans. Appetite 21, 255-272.

de Castro, J. M. (1994a). Family and friends produce greater social facilitation of food intake than other companions. Physiology and Behavior 56, 445-455.

de Castro, J. M. (1994b). Methodology, correlational analysis, and interpretation of diet diary records of the food and fluid intakes of free-living humans. Appetite 23, 179-192.

de Castro, J. M. (1997) Inheritance of social influences on eating and drinking in humans. Nutrition Research (In the Press).

de Castro, J. M., Bellisle, F., Feunekes, G. I. J., Dalix, A. M. \& De Graff, C. (1997). Culture and meal patterns: a comparison of the food intake of free-living American, Dutch, and French students. Nutrition Research (In the Press).

de Castro, J. M. \& Brewer, E. M. (1992). The amount eaten in meals by humans is a power function of the number of people present. Physiology and Behavior 51, 121-125.

de Castro, J. M., Brewer, E. M., Elmore, D. K. \& Orozco, S. (1990). Social facilitation of the spontaneous meal size of humans is independent of time, place, alcohol, or snacks. Appetite 15, 89-101.

de Castro, J. M. \& de Castro, E. S. (1989). Spontaneous meal patterns in humans: influence of the presence of other people. American Journal of Clinical Nutrition 50, 237-247.

de Castro, J. M. \& Elmore, D. K. (1988). Subjective hunger relationships with meal patterns in the spontaneous feeding behaviour of humans: evidence for a causal connection. Physiology and Behavior 43, 159-165. 
de Castro, J. M., McCormick, J., Pedersen, M. \& Kreitzman, S. N. (1986). Spontaneous human meal patterns are related to preprandial factors regardless of natural environmental constraints. Physiology and Behavior 38, 25-29.

De Luca, R. V. \& Spigelman, M. N. (1979). Effects of models on food intake of obese and non-obese female college students. Canadian Journal of Behavioural Science 11, 124-129.

Edelman, B., Engell, D., Bronstein, P. \& Hirsch, E. (1986). Environmental effects on the intake of overweight and normal weight men. Appetite 7, 71-83.

Feinleib, M., Garrison, R. J., Fabsitz, R., Christian, J. C., Hrubec, Z., Bohani, N. O., Kannel, W. B., Rosermas, R., Schwartz, J. T. \& Wagner, J. O. (1977). The NHLBI twin study of cardiovascular disease risk factors methodology and summary of results. American Journal of Epidemiology 106, 284-295.

Feunekes, G. I. J., De Graaf, C. \& Van Staveren, W. A. (1995). Social facilitation of food intake is mediated by meal duration. Physiology and Behavior 58, 551-558.

Forkman, B. A. (1991). Social facilitation is shown by gerbils when presented with novel but not with familiar food. Animal Behaviour 42, 860-861.

Frank, J. D. (1944). Experimental studies of personal pressure and resistance: I. Experimental production of resistance. Joumal of Genetic Psychology 30, 23-41.

Goldman, S. J., Herman, C. P. \& Polivy, J. (1991). Is the effect of a social model on eating attenuated by hunger? Appetite 17, 129-140.

Goran, M. I. \& Poehlman, E. T. (1992). Total energy expenditure and energy requirements in healthy elderly persons. Metabolism 41, 744-753.

Harlow, H. F. (1932). Social facilitation of feeding in the albino rat. Journal of Genetic Psychology 43, $211-221$.

Harlow, H. F. \& Yudin, H. C. (1933). Social behaviour of primates I. Social facilitation of feeding in the monkey and its relation to attitudes of ascendance and submission. Journal of Comparative Psychology 16, 171-185.

Hoyenga, K. T. \& Aeschleman, S. (1969). Social facilitation of eating in the rat. Psychonomic Science 14, 239240.

Hsia, L. C. \& Wood-Gush, D. G. (1984). Social facilitation in the feeding behaviour of pigs and the effect of rank. Applied Animal Ethology 11, 265-270.

James, W. T. (1960). The development of social facilitation of eating in puppies. Journal of Genetic Psychology 96, $123-127$.

King, M. B. (1993). Cultural aspects of eating disorders. International Review of Psychiatrics 5, $205-216$.

Krantz, D. S. (1979). A naturalistic study of social influences on meal size among moderately obese and nonobese subjects. Psychosomatic Medicine 41, 19-27.

Latane, B. (1981). The psychology of social impact. American Psychologist 36, 343-355.

Livingstone, M. B., Prentice, A. M., Coward, W. A., Strain, J. J., Black, A. E., Davies, P. S. W., Stewart, C. M., McKenna, P. G. \& Whitehead, R. G. (1992). Validation of estimates of energy intake by weighted-dietary record and diet history in children and adolescents. American Journal of Clinical Nutrition 56, 29-35.

Livingstone, M. B., Prentice, A. M., Strain, J. J., Coward, W. A., Black, A. E., Barker, A. E., McKenna, P. G. \& Whitehead, R. G. (1990). Accuracy of weighed dietary records in studies of diet and health. British Medical Journal 300, 708-712.

Mori, D., Chaiken, S. \& Pliner, P. (1987). 'Eating lightly' and the self-presentation of femininity. Journal of Personality and Social Psychology 53, 693-702.

Nisbett, R. E. \& Storms, M. D. (1972). Cognitive and social determinants of food intake. In Thought and Feeling: Cognitive Alteration of Feeling States, pp. 190-208 [H. London and R. E. Nisbett, editors]. Chicago: Aldine Publishing Co.

Pliner, P. \& Chaiken, S. (1990). Eating, social motives, and self-presentation in women and men. Journal of Experimental Social Psychology 26, 240-254.

Poehlman, E. T., Depres, J.-P., Marcotte, M., Tremblay, A., Theriault, G. \& Bouchard, C. (1986a). Genotype dependency of adaptation of adipose tissue metabolism after short-term overfeeding. American Journal of Physiology 25, E480-E485.

Poehlman, E. T., Tremblay, A., Depres, J.-P., Fontaine, E., Perusse, L., Theriault, G. \& Bouchard, C. (1986b). Genotype-controlled changes in body composition and fat morphology following overfeeding in twins. American Journal of Clinical Nutrition 43, 723-731.

Poehlman, E. T., Tremblay, A., Fontaine, E., Depres, J.-P., Nadeau, A., Dussault, J. \& Bouchard, C. (1986c). Genotype dependency of the thermic effect of a meal and associated hormonal changes following short-term overfeeding. Metabolism 35, 360-366.

Polivy, J., Herman, C. P., Younger, J. C. \& Jaeger, J. (1979). Effects of a model on eating behaviour: the induction of a restrained eating style. Journal of Personality 47, 110-117.

Price, R. A., Cadoret, R. J., Stunkard, A. J. \& Troughton, E. (1987). Genetic contribution to human obesity: an adoption study. American Journal of Psychiatry 144, 1003-1008.

Rajecki, D. W., Kidd, R. F., Wilder, D. A. \& Jaeger, J. (1975). Social factors in the facilitation of feeding in chickens: effects of imitation, arousal, or disinhibition? Journal of Personality and Social Psychology $\mathbf{5 2}$, 510-518. 
Redd, E. M. \& de Castro, J. M. (1992). Social facilitation of eating: effects of instructions to eat alone or with others. Physiology and Behavior 52, 749-754.

Schlettwein-Gsell, D., Barclay, D., Osler, M. \& Trichopoulou, A. (1991). Euronut SENECA study on nutrition and the elderly. Dietary habits and attitudes. European Journal of Clinical Nutrition 45, Suppl. 3, 83-95.

Sommer, R. \& Sommer, B. A. (1989). Social facilitation effects in coffee-houses. Environmental Behaviour 21, $651-666$.

Sommer, R. \& Steele, J. (1997). Social effects on duration in restaurants. Appetite (In the Press).

Sorenson, T. I. A., Price, R. A., Stunkard, A. J. \& Schulsinger, F. (1989). Genetics of human obesity in adult adoptees and their biological siblings. British Medical Journal 298, 87-90.

Stunkard, A. J., Foch, T. T. \& Hrubec, Z. (1986a). A twin study of human obesity. Joumal of American Medical Association 256, 51-54.

Stunkard, A. J., Harris, J. R., Pedersen, N. L. \& McClearn, G. E. (1990). The body-mass index of twins who have been reared apart. New England Journal of Medicine 322, 1483-1487.

Stunkard, A. J., Sorenson, T. I. A., Hanis, C., Teasdale, T. W., Chakraborty, R., Schull, W. J. \& Schulsinger, F. $(1986 b)$. An adoption study of human obesity. New England Journal of Medicine 314, 193-198.

Tolman, C. W. (1964). Social facilitation of feeding behaviour in the domestic chick. Animal Behaviour 12, 245-251.

Tolman, C. W. \& Wilson, G. F. (1965). Social feeding in domestic chicks. Animal Behaviour 13, $134-142$.

Wade, J., Milner, J. \& Krondl, M. (1981). Evidence for a physiological regulation of food selection and nutrient intake in twins. American Journal of Clinical Nutrition 34, 143-147.

Welty, J. C. (1934). Experiments in group behaviour of fishes. Physiological Zoology 7, 85-128.

Zajonc, R. B. (1980). Compresence. In Psychology of Group Influence, pp. 35-60 [P. B. Paulus, editor]. Hillsdale, NJ: Erblaum Press.

Zo eet Nederland (1992). Results of the Dutch National Food Consumption Survey. The Hague: Voorlichtingsbureau voor de Voeding.

\section{DISCUSSION OF THE PAPER}

\section{Comment by Richard Mattes}

Infant and twin studies have been undertaken to determine whether there may be a genetic basis for the chemosensory influence on food selection. With the exception of a heritable component for selected compounds (e.g. phenylthiocarbamide, taste; androstenone, smell), the preponderance of evidence fails to support a strong genetic basis for sensitivity to or preference for chemosensory stimuli in humans.

\section{Comment by Abayomi Akanji}

It is probably worth remarking that there is a striking heterogeneity in African countries regarding determinants of meal size and frequency. If the final document from the present workshop is aimed at reflecting global patterns, then it is necessary to incorporate aspects of this African perspective, although admittedly most of the information is anecdotal.

The principal determinants of meal size, variety and frequency in African countries are:

(1) food security; in most countries, the issue is not one of choice, but of what is available and can be afforded. Famine has devastated many Central and East African countries. In many others, political instability has devastated whole populations. In some, policies of the World Bank or International Monetary Fund have destroyed the middle class. And, in almost all countries, there are no viable government-supported food welfare programmes for the disadvantaged;

(2) rural $v$. urban domicile; urban residents have more choice and more money to decide on what they want to eat and when. They are also more subject to Western influences;

(3) social class; the higher classes essentially have meal patterns similar to those in the West. For the lower classes, the question is one of food insecurity; 
(4) ethnic divisions; even within countries, there is striking diversity of meal practices. In Nigeria for example, there are three major tribes and approximately 100 minor tribes, each with different cultural and feeding patterns. The major foods eaten and the ways they are prepared also differ strikingly;

(5) religion; mainly Christianity $v$. Islam $v$. Animism. No major or significant differences in meal patterns. The fact that Islam demands fasting during daylight hours during one holy month of Ramadan does not, in my opinion, significantly impact on overall meal patterns and frequency;

(6) other cultural practices; in earlier times, women were specially fattened to make them more attractive to men; men guarded jealously their 'pot-bellies' as a sign of wealth. These practices are steadily being rendered obsolete.

\section{Overall summary}

The primary determinant of meal size, frequency and variety is economics; food security. For the high-class, urban, literate resident, Western practices predominate. For the rural poor, meal frequency is two meals daily, a morning light meal and an evening heavy meal, depending on what is obtained from the farm and/or market. It is also the poor that may be more subject to religious, ethnic and other cultural influences on meal patterns. 